\title{
INTRODUCTION
}

\section{Fostering accessible technology and sculpting an inclusive market through regulation}

\author{
Delia Ferri ${ }^{\mathrm{a} *}$, G. Anthony Giannoumis ${ }^{\mathrm{b}}$ and Charles Edward O’Sullivan ${ }^{\mathrm{c}}$ \\ ${ }^{a}$ Department of Law, Maynooth University, Co. Kildare, Ireland; ${ }^{b}$ Department of Computer Science, \\ Oslo and Akershus University College of Applied Sciences, Oslo, Norway; ${ }^{c}$ Department of Law, \\ Maynooth University, Co. Kildare, Ireland
}

Technology has attracted an increasing level of attention within disability studies. Even though an ambivalent attitude towards technological innovation still remains (Sheldon 2003; Macdonald and Clayton 2013), several scholars appreciate that advances in technology have enabled more persons with disabilities than ever before to actively participate in society (Halvorsen 2010; Blanck 2014; Giannoumis 2014).

Disability studies' scepticism towards technology derives from the fear that technology becomes another way to 'fix' impairments, perpetuating and reinforcing the outdated medical approach to disability, which identified disability with impaired invalid bodies that needed to be cured, helped, assisted, 'supplemented' (ex pluribus Barnes and Mercer 2010; Oliver and Barnes 2012). In addition, some scholars see technology as another impairing barrier, rather than a facilitator or a tool to overcome existing obstacles (Jaeger 2013; Blanck 2014). Goggin and Newell (2003, $131 \mathrm{ff}$.), for example, affirm that digital technologies, have created a system of exclusion, further isolating people with disabilities.

These sceptical views, however, have been contrasted with a more positive approach towards the role that technology can play in eliminating societal barriers, in line with the social model of disability. The main feature of the social model is the conception of disability as a societal creation (ex pluribus Barnes 1991; Oliver 1996; Traustadóttir 2009; Oliver 2013). Disability is viewed as the consequence of environmental barriers. While the impairment is the functional limitation within the individual, disability is the loss or limitation of opportunities to take part in the normal life of the community on an equal level with others due to physical and social barriers. Without exploring the complex literature on the 'social model', it suffices to point out that some scholars addressed the role of technology in reducing the environmental and attitudinal barriers disabled people have commonly faced in the field of employment. Roulstone (1998), in particular, affirmed that the benefits of new technology are inherent in their potential to rehabilitate disabling environments. The study 'Stairway to Heaven?' released in 2007 (Fossestol 2007), was underpinned by the idea that ICT 'increases opportunities for participation in the workplace for persons with disabilities'. Some authors strongly argue in favour of enhancing the accessibility of the web, since this contributes to social inclusion (Berry 1999; Blanck 2008). Previous research has also demonstrated that the transition to education and employment requires accessible technology (Nordic Cooperation on Disability Issues 2007; Parker and Banerjee 2007).

*Corresponding author. Email: Delia.Ferri@nuim.ie 
In the last few years, the mounting criticism on the abstraction of the social model and its lack of attention towards everyday experiences of people with disabilities (inter alia Corker and Shakespeare 2002; Anastasiou and Kauffmann 2013) has gone hand in hand with the emergent recognition that technology may actually improve personal experiences. Some scholars have underlined the potential of technology in enhancing people's abilities. For example, Wey (2005) describes the potential roles for technology to help people with dementia by supporting memory, orientation and other cognitive abilities. In addition, Wey (2005) points out that technology enables activities that the individual is unable or is at a risk of being unable to do, encourages active involvement in daily activities, including social interactions, ensures the individual's safety, and supports and reassures caregivers. Even though technology is not per se adequate to reduce all the barriers, it can certainly be a means for a person with disability to retain choice and autonomy in his/her life (Ferri 2014; Giannoumis and Kline 2014). This is particularly true with regards to what is commonly defined 'accessible technology', which, according to the International Standardization Organization (ISO) and International Electrotechnical Committee (IEC) encompasses both universally designed technological products and assistive technology (AT).

Universally designed technologies are digital goods and services that are readily usable by the widest possible population without any modification. Universally designed technology relates to the principle of universal access, taking into account human differences and allowing all individuals to interact with the environment and society to the best of their ability. AT includes assistive, adaptive and rehabilitative devices aimed at compensating for functional limitations. It can be acquired commercially off-the-shelf, modified or customized, and covers a wide range of products intended to support the tasks and activities that people do during the course of everyday life by enabling the technology's user to perform tasks that would otherwise be difficult or impossible. AT can be items that are designed specifically for people with disabilities (e.g. communication boards) or the general population (e.g. cell phones) and range from high-tech (e.g. powered wheelchairs) to low-tech (e.g. Post-it notes). This broad scope of AT is reflected in the ISO classification system, which includes assistive products for personal medical treatment, orthoses and prostheses, assistive products for personal care and protection, for personal mobility, for housekeeping, furnishings and adaptations to homes and other premises, assistive goods for employment and vocational training, and assistive tools for recreation. AT also comprises Ambient Assisted Living (AAL) solutions (e.g. ubiquitous computing and sensing, ubiquitous communication, and intelligent user interfaces), although these are specifically targeted to older people, rather than to persons with disabilities.

Legal scholarship has started to focus on accessibility and accessible technology quite recently and has built upon the findings of disability studies (ex pluribus Easton 2012). The major impetus towards a widespread legal analysis on accessibility law and policies was derived by the entry into force of the UN Convention on the Rights of people with disabilities (UNCRPD, or simply 'the Convention'). The UNCRPD is currently the most relevant piece of international law in the field of disability and represents the benchmark against which to assess national and European Union legislation. It is widely recognized that the UNCRPD has been the most rapidly negotiated UN treaty, and one of the most groundbreaking pieces of legislation in the field of human rights. The Convention does not seek to create new rights for disabled persons; rather, it elaborates and clarifies existing human rights within the disability context. It is innovative, and it aims to ensure the active participation of persons with disabilities in political, economic, social, and cultural life, by accommodating their difference (ex pluribus Kayess and French 2008). 
The Convention fills an important gap in international law, and it is not an exaggeration to call it revolutionary as it is the first legally binding instrument that reflects the 'social model' of disability, i.e. the view that disability stems primarily from the failure of the social environment to meet the needs of people with disabilities, and not the narrower and traditional medical model.

The UNCRPD, in putting a great emphasis on accessibility, also highlights the role that accessible technology might play in the promotion and protection of the rights of people with disabilities. Accessibility features as a general principle of the UNCRPD (Article 3) and is laid down in Article 9 as a specific obligation. The latter provision imposes a range of duties on Parties to the Convention, making it clear that accessibility covers more than technical design specifications for products, information and signage or the built environment. Accessibility gives rise to specific applications in other substantive articles. Article 4 on general obligations refers to accessible information (subsection h); Article 13 deals with access to justice; Article 21 provides for access to information; Article 30 concerns access to cultural goods and services; Article 31 deals with accessibility of statistical and research data of relevance for the realization of the Convention; and Article 49 ensures that the UNCRPD is available in accessible formats. Article 20 UNCRPD is also relevant in this context. It recognizes personal mobility as a human right and provides that the states 'shall take effective measures to ensure personal mobility with the greatest possible independence for persons with disabilities'. This provision influences the supply of auxiliary tools for persons with disabilities, and underpins the removal of any restriction to the provision of technological aids to mobility. The UNCRPD juxtaposes the promotion of universally designed ICT with the provision of AT. It clarifies that the obligation to spread 'universal design', shall not exclude assistive devices for particular groups of persons with disabilities where this is needed. Article 4(1)(h) UNCRPD states that Parties to the Convention must 'provide accessible information to persons with disabilities about mobility aids, devices and assistive technologies, including new technologies, as well as other forms of assistance, support services and facilities'. In addition, Article 26 UNCRPD on habilitation and rehabilitation states that 'States Parties shall promote the availability, knowledge and use of assistive devices and technologies, designed for persons with disabilities, as they relate to habilitation and rehabilitation'. In general, the UNCRPD acknowledges the relevance and positive effects that accessible technology might play as a tool to allow people with disabilities to enjoy their rights.

Since its adoption, the UNCRPD has received widespread support and has been ratified by 154 States thus far. On 26 November 2009, the former European Community (now the European Union, or the 'EU') also acceded to the Convention. Hence, the UNCRPD has currently become the main benchmark against which to measure the adequateness of 'disability policy' in both Europe and the world at large.

Against this background, this Special Issue 'Fostering Accessible Technology and Sculpting an Inclusive Market through Regulation' gathers together different contributions that focus on how to enhance production, marketing and use of accessible technology. This Special Issue, in particular, endeavours to create a conceptual bridge between DISCIT and other projects, funded under the EU's Framework Programme $7,{ }^{1}$ such as Robolaw, ${ }^{2}$ and DREAM $^{3}$ and to gather within a single issue research on accessible technology conducted by different researchers across Europe using different disciplinary approaches.

Building upon previous academic studies and in light of the UNCRPD, accessible technology is considered a tool to increase autonomy and participation. On the one hand, this Special Issue acknowledges that universal design is a mechanism for achieving accessible ICT. On the other hand, it draws on previous research, which has shown that AT represents, 
at least to a certain extent, the conditio sine qua non for people with disabilities to enjoy their rights, such as the right to education, freedom of expression or the right to move (Borg, Larsson, and Östergren 2011; Ripat and Woodgate 2011).

In this Special Issue, the term 'regulation' is broader than 'law', as it includes legislation, soft law and 'private regulation' - e.g. common rules, memoranda of understanding, regulatory contracts, codes of conduct and voluntary agreements by which economic actors, social players, NGOs and organized groups establish themselves to voluntarily regulate and organize their activities. Standards, which are technical specifications for goods, services, or processes, are probably the most prominent and relevant form of 'private regulation' as there are key vehicles to develop accessible technology (Cafaggi and Renda 2012). Although, all the authors give account of several regulatory 'levels' (international, European and national), particular attention is paid to EU regulation.

This Special Issue is divided into three main parts, which coincide with three thematic strands. The first focuses on how to better shape 'hard' law in order to more fully promote accessible technology in three specific areas: copyright, product liability legislation and State aid. The second strand focuses on information and communication technology (ICT) and adopts a more inter-disciplinary style. All the authors included in this part have a background in ICT and combine a technical analysis with a socio-legal and political science approach, in order to examine the mediating factors involved in policy design and its implementation. Finally, the third strand introduces ethical and human rights discourse. The fil rouge among all these different contributions is not only provided by the focus on accessible technology, but also on the deliberate attempt to show or propose appropriate regulatory options that can nudge the market, and the society as a whole, in a more accessible direction. This Special Issue attempts to trace the pathway for a society in which people with disabilities enjoy the same opportunities as other people.

The first part includes three contributions written by Sganga, Bertolini and Ferri. These contributions adopt a legal approach and provide the reader with different perspectives on how to shape regulation with the intention of enhancing the rights of people with disabilities. These three contributions provide different perspectives on the design and implementation of accessible technology law, yet purport the same sense of urgency for reform. Sganga discusses access to knowledge and participation in cultural life for persons with disabilities. The author posits that copyright has traditionally represented an obstacle for accessible works. However, the author argues that we are witnessing a paradigm shift, caused in part by human rights advocates and the accelerated adoption of a new definition of the interplay between authors' rights and the right to take part in cultural life. Sganga examines not only UN and World Intellectual Property Organization (WIPO) treaties, but also EU and its Member States' responses to human rights obligations - focusing on legislative exceptions and collective licence agreements. Bertolini addresses a particular type of technology robotic prostheses. The author argues that the development of such devices is extremely complex and expensive, both in terms of ex ante research costs and potential ex post litigation costs, and shaping liability rules in order to provide incentives that are more favourable may prove of seminal importance. Pursuant to existing legislation, robotic prostheses are products, and thus subject to the EU Directive 85/374/EEC on Defective Product Liability. Ferri identifies specific failures that characterise the EU market for accessible technologies as a whole and examines the 'chicken-and-egg' conundrum in the industry's unwillingness to engage in experimental products, which require massive development and production costs, and its reluctance to invest in products without an expressed consumer demand. Against this background, she analyses the role of EU State aid law to adequately enhance the production of accessible technology. 
The second part includes Rice's, Giannoumis' and Huffacker's articles. These contributions are characterized by an inter-disciplinary approach and base their analyses mainly on existing reports, on studies and, in some cases, on qualitative interviews with stakeholders. Rice explores the goal of the European Commission to improve the quality and level of accessibility in mainstream ICT goods and services. The author analyses the legal implications of a new public procurement directive package, which contains stronger obligations on public bodies to include accessibility as mandatory requirements, and discusses the relevance of standardization in the context of public procurement legislation. Giannoumis adopts a political science approach and examines how public procurement policies for ICT, aimed at improving the accessibility of ICT for persons with disabilities, have converged internationally. The author explores convergence from a 'bottom-up' perspective, by examining the influence of networks of public and private actors on the design of public procurement standards for accessible ICT. Specifically, Giannoumis aims to answer how these actors and networks (varying in their level of coordination) have contributed to policy design in a unique area, public procurement of ICT goods and services. The article is empirically supported through the use of policy document data and semi-structured interviews. Finally, Huffaker examines the way in which governments implement and augment eAccessibility and, assesses the appropriateness of the eAccessibility EU legal framework in relation to the UNCRPD. He also examines national legislation, focusing on two case study countries - Ireland and Spain. These countries have been chosen as they represent high and low 'Measuring eAccessibility' scores, respectively. The particular technologies chosen for examination include websites, self-service terminals and mobile phone apps.

The third part of this Special Issue includes two contributions that address ethical issues. In particular, Palmerini explores the regulatory framework regarding ICT implanted into the body. This author adopts a more medical perspective and discusses how technology, while invasive and potentially affecting bodily integrity, serves qualified purposes, linked to other fundamental rights, and allows for human flourishing. The final contribution written by Gooding, Arstein-Kerslake and Flynn adopts a human rights perspective and a social model approach: it explores the use of assistive devices as a support for decision-making in exercising legal capacity for individuals with physical and cognitive impairments. The authors highlight the diversity of options for 'support for the exercise of legal capacity', showing how these options can assist people with various disabilities, and they investigate the boundaries of the state obligation to provide such support, including issues of practical implementation and resource allocation.

Overall, this Special Issue attempts to show, through a multifaceted and inter-disciplinary analysis, that different regulatory approaches might enhance accessible technology and its availability. Investigating the interrelations among different legal systems and different 'suppliers' of law (public and private), the contributions collected here also illustrate the interaction between law, political science, sociology and disability studies. All these articles, to varying degrees, remind us of the necessity of interdisciplinarity and of cross-cutting research that addresses, in a comprehensive fashion, complex societal challenges.

\section{Acknowledgements}

This special edition marks the completion of our work on Work Package 7 in the DISCIT Project. It has been a great pleasure and privilege for us to be guest editors of this Special Issue, and we would like to thank all the authors and peer reviewers for their highly valued work. We also wish to acknowledge the contribution of Mr Charles Edward O'Sullivan who joined us in April 2015 as Guest Assistant Editor. We also gratefully acknowledge the support given by Subhajit Basu and Ken Russell. 


\section{Conflict of interest disclosure}

No potential conflict of interest was reported by the authors.

\section{Notes}

1. The European Framework Programme 7 (2007 to 2013) is a funding mechanism for research and technological development in Europe.

2. For more information on Robolaw, see http://robolaw.eu/

3. For more information on DREAM, see http://www.disability-rights.eu/

\section{References}

Anastasiou, D., and J. M. Kauffman. 2013. "The Social Model of Disability: Dichotomy between Impairment and Disability." Journal of Medicine and Philosophy 38: 441-459.

Barnes, C. 1991. Disabled People in Britain and Discrimination. London: Hurst.

Barnes, C., and G. Mercer. 2010. Exploring Disability. Cambridge: Polity Press.

Berry, J. 1999. "Apart or A Part? Access to the Internet by Visually Impaired and Blind People, With Particular Emphasis on Assistive Enabling Technology and User Perceptions." Information Technology and Disabilities Journal 6 (3). Accessed April 15, 2015. http://itd.athenpro.org/ volume6/number3/article2.html.

Blanck, P. 2008. "Flattening the (Inaccessible) Cyberworld for People with Disabilities." Assistive Technology: The Official Journal of RESNA 20 (3): 175-180.

Blanck, P. 2014. eQuality: The Struggle for Web Accessibility by Persons with Cognitive Disabilities. New York: Cambridge University Press.

Borg, J., S. Larsson, and P. O. Östergren. 2011. "The Right to Assistive Technology: For Whom, For What, and By Whom?" Disability and Society 26 (2): 151-167.

Cafaggi, F., and A. Renda. 2012. "Public and Private Regulation. Mapping the Labyrinth." CEPS Working Paper. Accessed April 15, 2015. http://www.ceps.eu.

Corker, M., and T. Shakespeare. 2002. Disability/Postmodernity: Embodying Disability Theory. London: Bloomsbury Publishing.

Easton, C. 2012. "Revisiting the Law on Website Accessibility in the Light of the UK's Equality Act 2010 and the United Nations Convention on the Rights of Persons with Disabilities." International Journal of Law and Information Technology 20 (1): 19-47.

Ferri, D. 2014. "Deliverable 7.1. Analytical Framework for a Comparative Analysis of Accessible Technology Law and Policy." Accessed April 20, 2015. http://discit.eu/.

Fossestol, K. 2007. Stairway to Heaven? ICT POLICY, Disability and Employment in Denmark, The Netherlands, UK and Norway. Accessed April 15, 2015. www.afi-wri.no/stream_file.asp? iEntityId=2626.

Giannoumis, G. A. 2014. "Regulating Web Content: The Nexus of Legislation and Performance Standards in the United Kingdom and Norway." Behavioral Sciences \& the Law 32 (1): 52 75. doi:10.1002/bsl.2103.

Giannoumis, G. A., and J. Kline. 2014. "Deliverable 7.2 (D7.2). Active Citizenship through the Use of New Technologies - The Experiences of Three Generations of Persons with Disabilities." Accessed April 20, 2015. http://discit.eu/.

Goggin, G., and C. Newell. 2003. Digital Disability: The Social Construction of Disability in New Media. Lanham, MD: Rowman \& Littlefield.

Halvorsen, R. 2010. "Digital Freedom for Persons with Disabilities: Are Policies to Enhance e-accessibility and e-inclusion Becoming More Similar in the Nordic Countries and the US?" In European Yearbook of Disability Law. Vol. 2, edited by Lisa Waddington and Gerard Quinn, 77-102. Antwerp, Oxford: Intersentia.

Jaeger, P. 2013. "Internet Justice: Reconceptualizing the Legal Rights of Persons with Disabilities to Promote Equal Access in the Age of Rapid Technological Change." Review of Disability Studies: An International Journal 9 (1): 39-59.

Kayess, R., and P. French. 2008. "Out of Darkness into Light? Introducing the onvention on the Rights of Persons with Disabilities." Human Rights Law Review 8: 1-34.

Macdonald, S. J., and J. Clayton. 2013. "Back to the Future: Disability and the Digital Divide." Disability \& Society 28 (5): 702-718. 
Nordic Cooperation on Disability Issues. 2007. Provision of Assistive Technology in the Nordic Countries. Vällingby: Nordic Cooperation on Disability.

Oliver, M. 1996. Understanding Disability: From Theory to Practice. Basingstoke: Macmillan.

Oliver, M. 2013. "The Social Model of Disability: Thirty Years On.” Disability \& Society 28 (7): $1024-1026$.

Oliver, M., and C. Barnes, C. 2012. The New Politics of Disablement. Palgrave: Macmillan.

Parker, D. R., and M. Banerjee. 2007. "Leveling the Digital Playing Field: Assessing the Learning Technology Needs of College-Bound Students with LD and/or ADHD." Assessment for Effective Intervention 33 (1): 5-14.

Ripat, J., and R. Woodgate. 2011. "The Intersection of Culture, Disability and Assistive Technology." Disability and Rehabilitation. Assistive Technology 6 (2): 87-96.

Roulstone, A. 1998. Enabling Technology: Disabled People, Work, and New Technology. Buckingham, PA: Open University Press.

Sheldon, A. 2003. "Changing Technology." In Disabling Barriers - Enabling Environments, edited by J. Swain, S. French, C. Barnes, and C. Thomas, Chapter 23. London: Sage. Accessed April 15, 2015. http://disability-studies.leeds.ac.uk/files/library/Sheldon-chapter-for-alison.pdf.

Traustadóttir, T. 2009. "Disability Studies, the Social Model and Legal Developments." In The UN Convention on the Rights of Persons with Disabilities: European and Scandinavian Perspectives, edited by G. Quinn and O. M. Arnadottir, 3-16. The Hague: Brill-Martinus Nijohff.

Wey, S. 2005. "One Size Does Not Fit All: Person-centred Approaches to the Use of Assistive Technology." In Perspectives on Rehabilitation and Dementia, edited by M. Marshall, 202208. London: Jessica Kingsley. 